\title{
Crisis Communication in a New World
}

\author{
Reaching Multicultural Publics \\ through Old and New Media
}

\author{
Jesper Falkheimer \& Mats Heide
}

\begin{abstract}
Crisis communication is a growing field of research and practice. A weakness in the traditional research field is the lack of theoretical development and the isolated sender and mass communication focus. In the present paper, we challenge traditional research by focusing on the contemporary cultural and ethnic diversity in society from an audience-oriented media perspective. In the paper, we review earlier research on multicultural crisis communication. The discussion is based on secondary data on multicultural media use in Sweden and an Internet analysis focused on dialogue and community building. All together, the review and secondary data show that persons of foreign origin in Sweden have high access to ICT. This is an argument for directing crisis communication not only through traditional mass media, but also through new media. This is not only because of the simple reach of these channels, but also because of the increase in the quality and dialogue potential of these "great good places" (Oldenburg, 1999).
\end{abstract}

Keywords crisis communication, multicultural publics, public relations, media access, ICT

\section{Introduction}

We live in an "era of crises" (Lerbinger 1997). The statement does not necessarily mean that societies, organizations and individuals directly experience more physical crises, such as natural disasters or accidents, today than before. Instead, the statement is founded on the notion that we more often experience them indirectly, as distant but affective spectators. There are several well-known reasons for this crisis acceleration, among them globalization and the medialization of societies. Globalization is of particular interest in two respects. First, because images and stories of crises and threats tend to move faster and faster through the global media landscape, and second, because increasing mobility and migration mean that crises have to be managed and communicated in multicultural contexts. The concept of crisis may be used in several ways: psychologically (e.g., individual cognitive reactions), economically (e.g., effects on financial systems) or sociologically (related to social systems, groups and institutions). Our approach is mainly based on a sociological and organizational level focused on mediated communication and relations with certain groups in society. Naturally, it is not valid to define immigrants or persons of foreign origin as a homogenous group that differs in a simple way from one native group in a national context. Here, we do focus on cultural-ethnic differences, but 
based on the premise that these differences are social constructs that may be caused by several factors. The current social situation for a group is interpreted as more important for ethnic differences than is some kind of cultural heritage.

Crisis communication as practice and theory has traditionally been based on a mass communication paradigm. Sender-oriented perspectives and rational message distribution have dominated. In the present paper, however, we try to challenge this paradigm, by focusing on the contemporary cultural and ethnic diversity in society from an audience-oriented perspective. In Sweden, as an empirical example, approximately 22 percent of the population consists of persons with a foreign background, which means that they were either born in another country or that at least one parent was born abroad, according to Statistics Sweden (Nilsson, 2004).

Based on a finished research project on multicultural crisis communication funded by the Swedish Emergency Management Agency, we will first give a brief review of earlier research on multicultural crisis communication and public relations. Aiming to strengthen the audience-orientation, we will then focus on some areas of interest that we feel have been neglected: media use and new media, or more precisely - information and communication technology (ICT). This means that the uses and activities of multicultural publics are placed in the center of crisis communication. The aim of our paper is to give a critical review of existing research and to propose an audience turn in crisis communication, thus achieving theoretical development as well as practice. We are well aware that the most efficient communication strategy is based on a relational and interpersonal approach, using communities and social networks, and we have focused on these relations in other publications (e.g., Falkheimer \& Heide, 2006; 2008). However, because relationship building through networks and communities is very time-consuming and costly, crisis communicators must still focus on media strategies before and during crises. Thus, we find the media approach used here to be relevant.

\section{Pre-crisis Communication in Focus}

Crisis communication is a special interest area within the more general field of organizational crisis studies, which among other things embraces decision-making, forecasting potential crisis and producing plans for how to respond to the crisis so as to minimize damage and enforce recovery. Organizational crises are studied in several disciplines, for instance, management, organizational theory, political science, sociology, and psychology (Seeger, Sellnow \& Ulmer, 2003). Scholars interested in crisis communication are most commonly based in public relations, and their main interest is often in protecting and defending an organization's reputation.

A common theme in the literature on crisis communication is that crises are frequently described and explained as rigid stages. Some of the most common models depicting the life cycle of a crisis are Fink's (1986) four-staged model and Mitroff's (1994) five-staged model. However, the most common and regularly used model is the three-staged model, which divides a crisis into the pre-crisis, crisis, and post-crisis stages. In real life, a crisis is more of a process with no clear borders or stages, but to a certain extent these models have a pedagogical and analytical value. Scholars have traditionally focused on the last stage and viewed the crisis as an anomaly, but the biased interest in this stage is a rather reactive and defensive stance. In the comprehensive research on crisis communication, the pre-crisis stage is emphasized, and the crisis is understood as a natural part of an organization's lifecycle and development (cf. Seeger, Ulmer, Novak, \& Sellnow, 2005; 
Ulmer \& Sellnow, 2002; Weick, 1988), and some scholars (cf. Stern, 1997) highlight the crisis as a part of an organization's learning process. In brief, crises and "business as usual" are perceived here as normal organizational conditions.

Another common feature of the traditional research on crisis communication is to perceive crises as a result of some external threats in the surrounding environment. Crises are habitually viewed as objective and "real" things "out there", which strike and affect an organization. In contrast, Coombs (1999) emphasized that a crisis does not just happen; instead it slowly grows and develops. In most cases, a crisis begins with a trigger or with a person noticing and interpreting certain information. A natural connection to this reasoning is the epistemological perspective of social constructionism, which during the past fifteen years has strongly evolved and received a great deal of attention in organizational communication research. Social constructionism challenges many taken-for-granted concepts, such as organization, crisis, communication, culture, and power. The perspective developed as a reaction to the predominating positivistic research in the social sciences (Gergen, 1998). Distinguishing features of social constructionism are a questioning of "objective facts" (Burr, 1998), an emphasis on the active role people have in enacting a social reality, and on the important role of language in this process (Gergen, 1985). From the perspective of social constructionism, language is not a passive and simple medium that mirrors the reality "out there", and social interaction processes are important in the never-ending construction of reality. Implicitly, then, social constructionism is also a multicultural approach, as it focuses on socio-cultural understanding.

\section{Crisis as Organizing and Sensemaking}

Ever since publishing his book The Social Psychology of Organizing (1979, the fist edition was published in 1969), Karl E. Weick, one of the most prominent and influential scholars in the field of organization studies, has been a pioneer in the area of social constructionism. Weick's theory of organizing states, among other things, that an organization is continually produced and reproduced through communication between the organizational members. Further, the theory states that members' sensemaking processes enact the environment, i.e. it is a socially produced reality, as it is a product of the members' interpretation of available information. As a consequence, an organization will not react to changes in the environment in a totally rational, causal and predictable way, as is presumed by positivist scholars. Organizational members will not only try to make sense and react to information in the environment, but also actively enact the social reality of the organization, and act on the basis of this produced social reality.

Weick has an astounding breadth in his research, and not surprisingly he has also done research in the field of crisis communication (e.g., Weick, 1988, 1990). A social constructionist perspective on crises emphasizes communication and the social construction of reality. Thus, a crisis does not just arise by itself; the members' make sense of changes in- or outside the organization and slowly enact the crisis. According to Weick (1988), the sensemaking processes are affected by general undertakings, the members' perceptual capability, and their expectations. He understands crisis communication from an enactment perspective - communication as proactive activities.

An important concept in the field of crisis communication, discussed by Weick, is variety requisite. Originally, it was William Ross Ashby (1956) who formulated the "law of requisite variety" in the book An introduction to cybernetics. The law states 
that only variety can master variety, reducing disturbance and promoting harmonious order. In other words, the law suggests that a flexible system, with many options, has better possibilities to cope with changes. He emphasizes that people can only perceive categories and assumptions they have in their "cause maps", which are constructed from earlier experiences. Weick (1988:312) argues that: "[i]f those cause maps are varied and rich, people should see more, and good institutional memory would be an asset." Thus, if management is composed of mixed personnel with various backgrounds, interests, education, etc., an organization ought to have better possibilities to operate and function in a complex and unpredictable world. Further, the variety requisite is an important advantage in an increasingly multicultural world. As an example of the variety requisite in practice, the Swedish Police Service can be mentioned. Traditionally, they have recruited white males with a working-class or middle-class background. However, in recent years, the Swedish Police Service has actively searched for police aspirants among males and females with a multicultural background (Polisen, 2006). With a more varied personnel, the Police Service is gradually trying to increase their credibility and build up good relations, for example with youths in housing areas mainly composed of first and second generation "immigrants". To sum up, to optimize multicultural crisis communication, complex problems must be met with complex solutions, carried out by complex and heterogeneous organizations.

\section{A Cultural Approach}

Although Weick has made some important contributions to the field of crisis research, he does not address the communicative essence and dynamic nature of the relationship between an organization and its external publics (Lee, 2005). Lee emphasizes that crisis communication is doomed if the significance of organization-stakeholder relationships and communication is not appreciated. Earlier research indicates that an audience-orientation to crisis communication has not been addressed properly. Further, Lee claims that we now know rather little about what multicultural groups expect and how they evaluate and express themselves during a crisis. The consequences are that the activities of different publics and the dynamic nature of the crisis communication process are overlooked. According to the same logic, the role of the media in these processes is not reflected on from the perspective of audience access or use. The lack of cultural contextualization is another characteristic of crisis communication, even though there are exceptions. Defining culture as "systems of meaning group members acquire through experiential apprenticeship" (Banks, 2000:12), and viewing communication as a basically cultural process, we mean that crisis communication theory must move closer to cultural theory, for example by focusing on publics as interpretive communities. When we turn to the field of intercultural communication, we find that a great part of this research is quite traditional. Most researchers try to capture a complex, situational and dynamic phenomenon such as cultural identity using simple causal models. Instead, we find the research on cultures conducted by anthropologists more fruitful and nuanced (e.g., Eriksen, 1993). They use ethnicity as a concept to describe and understand cultural group identities. Ethnicity is defined in a social constructionist sense, as something that is dynamic, situational and that depends on the social context, and as something that everyone is a part of in one way or another. This means that ethnicity as a social formation is relational - it develops as a reaction to social pressure. If one accepts this conclusion, then there is a direct link to crisis communication, and there are case studies 
showing that ethnic differences seem to escalate during crises (even though the mass media tend to overestimate them). For example, this seems to have been the case during the 1998 Gothenburg Fire in Sweden, which killed 63 young people and injured 213, most of them of foreign origin.

Mutual and lasting relationships with important publics are requirements for a more optimistic perspective on crisis communication. As a consequence, issues management, risk communication, relationship building and dialogue become important parts of the interest of crisis communication scholars. We find the relationships between organizations-publics/audiences especially interesting. It is only in and through communication that constructive relationships can be nurtured and restored.

\section{Trends in Multicultural Media Access and Use}

In media research, it has been a standing conclusion for at least two decades that technological, economic, cultural and social changes have led to an increasingly diversified media market and audience. The growth of both new and traditional media, globalization of media content and audience segregation are problems as well as opportunities from a public relations perspective. It is true that it has become more difficult to reach a mass audience at the same time. At the same time, increasing diversity and structural changes in the media have created new opportunities for adjusting messages and getting closer to micro-audiences. Also, from a societal perspective, the development has decreased the risks that one authoritarian media source can rule the public sphere. McQuail (2005:138) has illustrated the historical development using four audience models: a unified model, a pluralist model, a centre-periphery model and a fragmented model.

The centre-periphery-model (McQuail, 2005:138) illustrates a society in which there is still a national center (e.g. in Sweden dominated by public service broadcasting and the local daily press), but an increasing development of isolated micro-media audiences. Young people as well as people of foreign origin may be viewed as periphery audiences (in short we will present empirical findings that both support and nuance this proposition). One crucial issue here is whether these periphery audiences are temporary or permanent. Using the temporary explanation, the argument goes that these fragmented audiences will slowly become socialized into the mainstream media structure. This we have yet to see.

\section{Media Access among Persons of Foreign Origin}

There are few empirical studies focusing on media access and use among persons of foreign origin. One exception is an aggregated analysis based on ten years of collected media surveys in Sweden, performed by Andersson (2005) at The Newspaper Research Programme, Göteborg University. Although the results are based on a rather limited sample, as few persons of foreign origin tend to answer these surveys, they do give some insights. The analysis has excluded persons with a Nordic background, because earlier research (Weibull, 2005) has shown that there are few differences in this context.

Andersson's (2005) analysis uses a concept of immigrant based on the Swedish statistical definition. This means that an immigrant is either a person who was born in another country (first-generation immigrant) or a person who has one or two parents who were born abroad (second-generation immigrant). This definition places 22 percent of the Swedish population into the category. The first-generation immigrants stand for 
10 percent and the second-generation immigrants for 12 percent (Nilsson, 2004). The surveys were answered by fewer first-generation immigrants than second-generation immigrants, and the results may only be interpreted as valid for persons who speak Swedish. Andersson (2005:41) concludes that the results probably slightly overestimate media access and use among immigrants. On the other hand, the persons who answered the surveys reflected the immigrant population in Sweden rather well: they were younger than average Swedes, had lower incomes and more often lived in urban environments.

One may initially ask why persons with a foreign background differ from native Swedes when it comes to media access and use. One reason is the fact that these persons have not been socialized into a certain and national media tradition the way native Swedes have. Media use is cultural and not only a rational function that one chooses from day to day. Media use is implicitly and ritually learned through interaction with socializing agents. Media use and understanding are, in other words, a form of cultural competence. Another obvious reason behind differences is the language. This is mostly valid for first-generation immigrants and older persons. One may speak of a language competence that also is linked to a presupposition of cultural competence. A third reason is not really a competence, but it is also linked to socialization. It regards the issue of trust in social institutions and the mass media. To many persons of foreign origin and from non-Western countries, the mass media are viewed as part of an authoritarian regime, as only reproducing the official state discourse. This is especially valid during crises, when authoritarian regimes tend to increase their control of the mass media.

The empirical analysis shows minor differences in media access between persons with a foreign background and native Swedes. Access to television is 9 percent higher among native Swedes than first-generation immigrants. Access to cable, satellite and digital television is, on the other side, somewhat higher among persons with a foreign background (especially the first generation). One explanation, besides the fact that there may be a greater interest in watching television from one's native country, is that persons with a foreign background more often live in apartments where this technology is easier to find. There are no relevant differences in access to telephones or mobile telephones. There is no difference when it comes to access to Internet, which is of increasing importance in crisis communication. In first-generation immigrants' households, there is in fact a higher access to Internet than in native Swedish households.

All together, the survey shows that the differences in media access are not very large. There is one exception: newspapers. About 75 percent of Swedish households subscribe to a newspaper. But among first-generation immigrants from countries outside Europe, hardly one-third of households subscribe to a newspaper and there is also a gap in relation to other groups.

\section{Media Uses and Minority Media}

Regarding media use, there is an obvious but not clear relationship to media access. People may read newspapers even though they do not have a subscription. But, according to the surveys, there are still major newspaper differences. Two explanatory variables are that the respondents, reflecting the statistical group, are younger than average Swedes and have lower incomes. Free newspapers such as Metro have many readers among people of foreign origin as well as youngsters, and they have established themselves as complements to the subscribed papers. A study by Wadbring (2003) showed that, in the big cities, people of foreign origin more often read free papers than do native Swedes. 
There are also differences between these populations when it comes to tabloid newspapers. Variables such as age, income and education are valid explanations behind this, but the form of distribution (sold in shops) is certainly of importance. The tradition of subscribing to newspapers has few comparisons outside Sweden. In any case, during acute crises, traditional newspapers are usually too slow to be of major interest for communicators or audiences. On the other hand, they do have an important role in the pre- and post-crisis stages, giving attention to risks and trying to explain causal crisis relationships (not seldom by constructing a simple story of heroes and scapegoats).

Broadcasting media are crucial during crises. The survey shows some relevant differences between native Swedes and persons with a foreign background. All together, the rate of listening to or viewing the top Swedish radio and television channels is much lower among persons of foreign origin. In general, when it comes to radio and television news, the predominating shows are, in descending order: P4 local news, Ekot national news, commercial station news (radio) and Aktuellt national news, Rapport, commercial TV news and regional news (television). The order is similar among native Swedes and persons of foreign origin, but more first- and second-generation immigrants view commercial television news (TV4).

There is a need for more empirical research on the issues handled above, especially from a qualitative perspective that tries to understand how these "statistical groups" really choose media and create meaning before, during and after crises.

Leaving the mainstream media behind us, there is a growing field of minority media that should have certain importance for multicultural crisis communication. Until lately, the minority media in Sweden have been a blind spot in research. But in 2005, Camauër presented an initial mapping of the field, on behalf of the National Board of Psychological Defence. Minority media are defined as media that are directed towards, and/or are of special interest to, minorities as minorities (Camauër, 2005:12). In a broad sense, minorities can be defined in many ways, but in this case, the focus is on ethnic minorities. The ethnic minority media are also diverse: they may be communicated in different languages, have or not have public support, be commercial or non-commercial, directed towards local as well as trans-national audiences and have very different content profiles. Camauër does not write very much about the roles or opportunities of minority media before, during or after crises, but it is obvious that minority media are often neglected by crisis managers and communicators, who lack knowledge about these media. The mapping shows that there are around 370 minority media in Sweden and that print media and radio are the most developed channels regarding reach, ethnic range and strength.

\section{New Opportunities with ICT}

Information and communication technology (ICT) is a hybrid medium; it is a multifaceted medium with a potential for both interpersonal and mass communication (Morris $\&$ Ogan, 1996). The most frequently used ICT media are e-mail, websites and discussion groups. Some of the most important characteristics of ICT are its interactivity, asynchronous nature, and relatively fast communication at a relatively low cost. The asynchronous mode of communication can be a benefit to people who have difficulties expressing their opinions in public due to linguistic problems (cf. Garton, Haythornthwaite, \& Wellman, 1997; Garton \& Wellman, 1995). Asynchronous communication gives the communicators time to express and explain their views. This feature can be a 
great advantage for multicultural publics, who do not have a complete mastery of their new language. Wellman and Gulia (1999) underline that ICT can unite the "two-step flow of communication" into one step, by combining the fast transmission of mass media with the persuasiveness of interpersonal communication. ICT offers increased possibilities for organizations to display and transmit information at high speed, and it enables storage of almost infinite amounts of information. Using ICT, organizations can provide an endless flow of information of all kinds, such as news, press releases, strategies, "facts", and corporate social responsibility reports, which can be utilized in a crisis situation. However, much of the public relations literature focuses on ICT as a monologic communication medium intended for storage and dissemination of information (Kent \& Taylor, 1998).

ICT is also opening up opportunities for the creation of new communicative environments independent of time and space (e.g., Castells, 2000). Use of the interactive and dialogical function of ICT is a prerequisite for organizations that wish to establish and maintain online or virtual community relations. On the Internet, millions of people are involved in virtual social relationships. The members of virtual communities are associated through a common practice or interest, not through the desire to reach a common goal or through social characteristics. Most of the virtual communities are specialized in a certain narrow field. In this discursive arena, likeminded people can develop their interests and the practices in which they are engaged (Slevin, 2000).

\section{Great Good Places}

The American sociologist Ray Oldenburg's term "third place" is used consistently to explain the use of chat rooms and bulletin board systems. Oldenburg (1999) has a romantic view of public places such as barbershops, cafés, bars, and bookstores, where people in a local community can meet and discuss things that are perceived as important. The modern man longs, according to Oldenburg, for the quickly disappearing public spaces - "great good places" or "third places" - which offer a break from the demands of everyday life. They serve as community maintainers, which strengthen the relationships between members through playful social interaction and communication. Third places are complicated to develop and maintain, without centralized "town squares" and with traditional neighborhoods abandoned for more private subdivision developments (Soukup, 2006). Traditional third places and computer-mediated contexts have several similar functions and features in common, for an example the possibility to escape for a while from ordinary life and socialize and informally discuss import issues with others. There are, however, several differences between CMC contexts and third places (Soukup, 2006). One difference is the "realness" - CMC contexts are simulations of a third place, but are not real physical places. Another difference is that CMC contexts are independent of any geographically localized community. Oldenburg maintains that there are three key characteristic differences between traditional third places and third places online; real third places emphasize localized community, are social levelers, and are accessible. Online communities exist autonomous of any local community, but can be used to support and strengthen local communities. Soukup (2006) reminds us that there are several economic and sociological barriers that prevent people in a society from becoming members of virtual communities. This phenomenon, often called the digital divide, raises many questions, not least concerning democracy and civic rights. The usual sociological variables - income, education, sex, age, and ethnic origin - explain societal 
differences in access to and use of the Internet. However, Soukup emphasizes that not even the traditional third places are necessarily as accessible as Oldenburg proclaims. Moreover, third places were intended to strengthen relationships within a single community, not to be multicultural (Soukup, 2006). But in the Swedish empirical context, which we have discussed earlier, ICT may offer several advantages for organizations in their efforts to build and maintain relationships with multicultural publics.

\section{Advantages and Principles of ICT}

Stakeholder activism is a common issue in the literature on crisis communication. ICT is the main medium for activist groups and organizations, and they seem to use the complete potential of ICT, both the information dissemination and dialogue functions. One great advantage of ICT is the possibility for financially weak organizations, communities or individuals to make their voices heard (Heath, 1998; Taylor, Kent, \& White, 2001). It is quite easy for publics to distribute and make their opinion public through the Internet. Individuals can send e-mail to authorities, companies, interest groups, and to other individuals in their acquaintanceship. Through discussion groups, individuals can reach an almost unlimited number of people for information distribution, discussions, and for establishing and maintaining communities of interest. The Internet also allows people to search for and find peers with the same interests and opinions. ICT gives organizations increased possibilities to become involved in interactive public dialogue, which was previously a difficult project requiring enormous resources (Heath, 1998). Consequently, ICT can have a democratizing effect, when communicators constantly can share their opinions and develop trustful relationships. Thus, ICT can be seen as a medium that allows publics to become powerful and attract the attention of organizations, thus minimizing the power gap (Coombs, 1998).

Kent and Taylor (1998) propose five principles to guide the transition from an information-oriented use of websites to a dialogic use and community building. The first principle is to set up a dialogic loop that offers feedback from an organization to its publics. This allows publics to receive answers to their questions and the organization has the opportunity to respond to questions, concerns and problems. Only when a dialogic loop is initiated can we talk of real interactivity between the participants. The second principle states that the included information must be of general significance to each of the publics. Further, Kent and Taylor underline that the organization ought to provide information that is of value, and that information distributed automatically is more appreciated than information publics themselves have to request. Valuable information coincides with the interests, values and concerns of publics, and makes a stabile ground for a dialogue between informed partners. The third principle declares that a website should attract repeat visits. This can be attained with new and updated information on the news sites and FAQ (frequently asked questions) as well as with online functions such as special forums and online experts who help visitors with their problems. According to Kent and Taylor, dialogic strategies are more desirable than informational strategies, even though information is an important part of any website. However, the unique aspect of ICT, which is to communicate in an interpersonal mode with a mass audience, is rather unusual in a professional and an organizational context. The fourth principle emphasizes the significance of usability, i.e. an intuitive and easy web interface, which makes it easy for visitors to orientate and find the information they 
are looking for. Finally, the fifth principle warns us about web links that lead visitors to other websites, such as commercials.

Information and communication technology (ICT) is custom-made for crises (Coombs, 1999). Access to and processing of information are vital throughout a crisis, and continuing interactivity, dialogues and community relations are important from a crisis perspective. Nevertheless, up to this point, little is known about organizations' use of ICT in crises (Taylor \& Perry, 2005). And it still seems that organizations are generally missing the interactive potential of ICT (cf. Taylor, Kent, \& White, 2001). To conclude, ICT is not the key to Pandora's box and it is not a panacea for all communication problems. Although ICT certainly has several advantages when it comes to crisis communication with different publics. For example, a web portal in combination with a discussion group offers the possibility to foster informal social interactions between publics and an organization.

\section{Final Remarks and Conclusions}

From a practitioner's perspective, the multicultural context challenges traditional mass communication strategies and messages. Despite the relevance of empirical case studies that have dominated the field of crisis communication, there is a need for theoretical development and a turn towards the audience, media uses and constructions of crisis. In the present paper, we have analyzed crisis communication by reviewing some findings in crisis communication research, empirical surveys on media use and access, and the characteristics of new media. Using an audience-oriented framework of analysis, we have tried to develop the notion of crisis communication as a contemporary practice.

There are problems with traditional segmentations of target groups, especially when it comes to multicultural diversity. As pointed out here, ethnicity as a cultural collective identity may be analyzed as a dynamic construction depending on the social and situational context. This means that traditional intercultural communication, based on national cultural comparisons, is rejected.

The secondary data on media use in Sweden among multicultural publics show that ICT use is at the same level as or higher than among native Swedes. This must be viewed as an opening and possibility to build future long-lasting relationships with these groups, and to promote trust, which is of primary importance during operative crises. In the paper, we also present reference material that shows the importance of minority media. All together, the review and secondary data reveal the need to direct crisis communication not only through traditional mass media, but also through micro and new media. This is not only because of the simple reach of these channels, but also because of the increase in quality and the dialogue potential of these great good places. The use of new media before, during and after crises is especially relevant from a multicultural perspective. The Swedish Emergency Management Agency (since 2009 the Swedish Civil Contingencies Agency) has launched a specific web portal to be used during all kinds of societal crises (www.krisinformation.se). Even though the idea seems interesting, there is one obvious problem from a multicultural perspective. How can we lead people to this specific web address?

There is an obvious empirical limitation of this paper, we look only at Sweden, but future research may show that the tendencies seen here are valid for several similar countries. There is also a need for more qualitative research in this field. 


\section{References}

Andersson, U. (2005) Nya svenskar och svenska medier [New Swedes and Swedish Media] (Arbetsrapport nr. 34). Göteborg: Institutionen för Journalistik och Masskommunikation.

Ashby, W.R. (1956) An Introduction to Cybernetics. London: Chapman \& Hall.

Badaracco, C.H. (1998) 'The Transparent Corporation and Organized Community', Public Relations Review, 24(3): 265-272.

Banks, S.P. (2000) Multicultural Public Relations: A Social-interpretive Approach (2. ed.). Ames, IA: Iowa State University Press.

Burr, V. (1998) 'Overview: Realism, Relativism, Social Constructionism and Discourse', in Parker, I. (ed.), Social Constructionism, Discourse and Realism. London: Sage.

Camauër, L. (2005) Minoritetsmedier och minoritetsmediepolitik i Sverige [Minority Media and Minority Media Politics in Sweden]. Stockholm: Styrelsen för psykologiskt försvar.

Castells, M. (2000) The Rise of the Network Society (2. ed.). Malden, MA: Blackwell.

Coombs, W.T. (1998) 'The Internet as Potential Equalizer: New Leverage for Confronting Social Irresponsibility’, Public Relations Review, 24(3): 289-303.

Coombs, W.T. (1999) Ongoing Crisis Communication: Planning, Managing, and Responding. Thousand Oaks, CA: Sage.

Eriksen, T. H. (1993) Ethnicity and Nationalism: Anthropological Perspectives. London: Pluto Press.

Falkheimer, J., \& Heide, M. (2006) 'Multicultural Crisis Communication: Towards a Social Constructionist Perspective', Journal of Contingencies \& Crisis Management, 14(4).

Falkheimer, J. \& Heide, M. (2008) Kriskommunikation i ett globalt samhälle. KBM:s temaserie 2008:4. Stockholm: Krisberedskapsmyndigheten.

Fink, S. (1986) Crisis Management: Planning for the Inevitable. New York, NY: American Management Association.

Garton, L., Haythornthwaite, C., \& Wellman, B. (1997) 'Studying Online Social Networks', Retrieved 200208-09, from http://ascusc.org/jcmc/vol3/issue1/garton.html

Garton, L., \& Wellman, B. (1995) 'Social Impacts of Electronic Mail in Organizations: A Review of the Research Literature', in Burleson, B.R. (ed.), Communication Yearbook 18: 434-453. London: Sage.

Gergen, K.J. (1985) 'The Social Constructionist Movement in Modern Psychology', American Psychologist, 40(3): 266-275.

Gergen, K.J. (1998) 'Constructionism and Realism: How are We to Go On?', in Parker, I. (ed.), Social Constructionism, Discourse and Realism. London: Sage.

Heath, R.L. (1998) 'New Communication Technologies: An Issues Management Point of View', Public Relations Review, 24(3): 273-288.

Kent, M.L., \& Taylor, M. (1998) 'Building Dialogic Relationships Through the World Wide Web', Public Relations Review, 24(3): 321-334.

Lee, B.K. (2005) 'Crisis, Culture, Community’, in Kalbfleisch, P.J. (ed.), Communication Yearbook 29 (pp. 275-309). Mahwah, NJ: Lawrence Erlbaum.

Lerbinger, O. (1997) The Crisis Manager: Facing Risk and Responsibility. Mahwah, NJ: Erlbaum.

McQuail, D. (2005) McQuail's Mass Communication Theory (5. ed.). London: Sage.

Mitroff, I.I. (1994) 'Crisis Management and Environmentalism: A Natural Fit', California Management Review 36(2): 101-114.

Morris, M., \& Ogan, C. (1996) 'The Internet as Mass Medium', Journal of Communication 46(1): 39-50.

Nilsson, Å. (2004) Immigration and Emigration in the Postwar Period (No. 2004:5). Stockholm: Statistics Sweden.

Oldenburg, R. (1999) The Great Good Place: Cafés, Coffee Shops, Bookstores, Bars, Hair Salons, and Other Hangouts at the Heart of a Community. New York: Marlowe.

Polisen. (2006) Vill du bli polis? [Do you want to become a policeman? The Swedish Police Service]. Retrieved June 22, 2006, from http://www.polisen.se/inter/nodeid=5980\&pageversion=1.html

Seeger, M.W., Ulmer, R.R., Novak, J.M., \& Sellnow, T. (2005) 'Post-crisis Discourse and Organizational Change, Failure and Renewal', Journal of Organizational Change Management 18(1): 78-95.

Seeger, M. W, Sellnow, T. L., \& Ulmer, R. R. (2003). Communication and Organizational Crisis. Westport, CT: Praeger.

Slevin, J. (2000) The Internet and Society. Cambridge: Polity Press.

Soukup, C. (2006) 'Computer-mediated Communication as a Virtual Third Place: Building Oldenburg's Great Good Places on the World Wide Web', New Media \& Society 8(3): 421-440.

Stern, E. (1997) 'Crisis and Learning: A Conceptual Balance Sheet', Journal of Contingencies \& Crisis Management 5(2): 69-87.

Taylor, M., Kent, M.L., \& White, W.J. (2001) 'How Activist Organizations are Using the Internet to Build rRelationships’, Public Relations Review 27(3): 263-284. 
Taylor, M., \& Perry, D.C. (2005) 'Diffusion of Traditional and New Media Tactics in Crisis Communication', Public Relations Review 31(2): 209-217.

Ulmer, R.R., \& Sellnow, T.L. (2002) 'Crisis Management and the Discourse of Renewal: Understanding the Potential for Positive Outcomes of Crisis', Public Relations Review 28(4): 361-365.

Wadbring, I. (2003) En tidning i tiden? Metro och den svenska dagstidningsmarknaden. Göteborg: Institutionen för journalistik och masskommunikation.

Weibull, L. (2005) 'Sverige i tidningsvärlden' in Bergström, A., Wadbring, I. \& Weibull, L. (eds.) Nypressat. Göteborg: Institutionen för journalistisk och masskommunikation.

Weick, K.E. (1979) The Social Psychology of Organizing (2. ed.). Reading, MA: Addison-Wesley.

Weick, K.E. (1988) 'Enacted Sensemaking in Crisis Situations', Journal of Management Studies 25: 305-317.

Weick, K.E. (1990) 'The Vulnerable System: An Analysis of the Tenerife air Disaster', Journal of Management 16(3): 571-593.

Wellman, B., \& Gulia, M. (1999) 'Virtual communities as communities: Net surfers don't ride alone', in Smith, M.A. \& Kollock, P. (eds.) Communities in Cyberspace (pp. 167-194). London: Routledge.

JESPER FALKHEIMER, Ph.d., Associate Professor, Department of Communication Studies, Lund University, jesper.falkheimer@iks.lu.se

MATS HEIDE, Ph.d., Associate Professor, Department of Communication Studies, Lund University, mats.heide@iks.lu.se 